\title{
POLLACK (Detlef), PICKEL (Gert), eds., Religiöser und kirhlicher Wandel in Ostdeutschland 1989-1999
}

(Changement religieux et transformation ecclésiale en Allemagne de l'Est 1989-1999) Opladen (All.), Leske-Budrich, 2000, 391 p. (tableaux, graphiques) (Veröffentlichungen der Sektion « Reli-gionssoziologie » der Deutschen Gesellschaft fur Soziologie) (Publications de la section «sociologie de la religion » de la société allemande de Sociologie)

\section{Claire de Galembert}

\section{(2) OpenEdition Journals}

\section{Édition électronique}

URL : http://journals.openedition.org/assr/20813

DOI : $10.4000 /$ assr.20813

ISSN : $1777-5825$

\section{Éditeur}

Éditions de l'EHESS

\section{Édition imprimée}

Date de publication : 1 juin 2001

Pagination : 106-107

ISBN : 2-222-96704-X

ISSN : 0335-5985

\section{Référence électronique}

Claire de Galembert, « POLLACK (Detlef), PICKEL (Gert), eds., Religiöser und kirhlicher Wandel in Ostdeutschland 1989-1999", Archives de sciences sociales des religions [En ligne], 114 | avril-juin 2001, document 114.36, mis en ligne le 19 août 2009, consulté le 21 septembre 2020. URL : http:// journals.openedition.org/assr/20813; DOI : https://doi.org/10.4000/assr.20813 


\section{POLLACK (Detlef), PICKEL (Gert), eds., Religiöser und kirhlicher Wandel in Ostdeutschland 1989-1999}

(Changement religieux et transformation ecclésiale en Allemagne de l'Est 1989-1999) Opladen (All.), Leske-Budrich, 2000, 391 p. (tableaux, graphiques) (Veröffentlichungen der Sektion « Reli-gionssoziologie » der Deutschen Gesellschaft fur Soziologie) (Publications de la section « sociologie de la religion » de la société allemande de Sociologie)

\section{Claire de Galembert}

\section{RÉFÉRENCE}

POLLACK (Detlef), PICKEL (Gert), eds., Religiöser und kirhlicher Wandel in Ostdeutschland 1989-1999, (Changement religieux et transformation ecclésiale en Allemagne de l'Est 1989-1999) Opladen (All.), Leske-Budrich, 2000, 391 p. (tableaux, graphiques)

(Veröffentlichungen der Sektion « Reli-gionssoziologie » der Deutschen Gesellschaft fur Soziologie) (Publications de la section « sociologie de la religion » de la société allemande de Sociologie)

1 Quel est l'impact de l'effondrement du communisme sur la situation religieuse estallemande? Pourquoi cet effondrement ne s'est-il pas traduit - comme le pronostiquaient certains et le laissaient penser les évolutions religieuses des pays relevant de l'ex-Union soviétique - par une revalorisation du religieux dans le champ social ? Comment expliquer ce que Jagodzinski nomme une « stagnation » religieuse se caractérisant par une indifférence durable à toute forme d'offres religieuses, que cellesci émanent des Églises ou des nouveaux mouvements religieux? Dans quelle mesure la théorie de la sécularisation qui implique un niveau de différenciation, d'individualisation et de pluralisation est-elle pertinente pour expliquer ce très bas niveau de religiosité de la population de l'ex-R.D.A.? Telles sont les interrogations 
auxquelles, près de dix années après la Wende, les différents contributeurs de l'ouvrage dirigé par D.P. et G.P. cherchent à apporter des réponses.

2 Le matériau empirique - tant quantitatif que qualitatif - sur lequel se fondent les analyses présentées dans l'ouvrage est aussi riche que divers. Il se compose d'une part d'enquêtes statistiques donnant lieu à des comparaisons des formes de religiosité ou de non-religiosité des Allemands de l'Ouest et des Allemands de l'Est (D.P./G.P., Denz), des analyses de rapports entre offre et demande religieuse (Jagodzinski) et des études comparatives confrontant Länder de l'Ouest/Länder de l'Est visant à mesurer l'impact de la religion (ou de l'absence de religion) sur la rigueur morale (Meulemann), la xénophobie (McCutcheon) ou encore les attitudes électorales aux législatives de 1998 (Jacobs).

3 Cet aperçu macrosociologique est enrichi de plusieurs enquêtes qualitatives. Parmi elles, on retiendra en particulier la contribution de Döhnert relative à la perpétuation de la Jugendweihe (cette confirmation laïque qui formait l'un des rituels les plus ancrés de la religion séculière mise au point par le régime est-allemand) dans l'Allemagne réunifiée, celle d'Hartmann au sujet des affiliations (Kirchenentritt) d'une petite minorité d'Allemands de l'Est aux Églises depuis la réunification, ainsi que celles de Schmied et de Storch sur le rôle de la religion dans les phases critiques de l'existence, celle de Schmied portant sur la religion et la mort, celle de Storch sur le rôle joué par la religion pour surmonter le choc de la Wende.

$\mathrm{Au}$ regard de la faible demande religieuse que font ressortir les statistiques, s'impose la conclusion que la politique antireligieuse de R.D.A. ainsi que l'imposition d'une religion politique avec ses mouvements et ses rituels sont parvenues à "immuniser " durablement les Allemands de l'Est contre la religion. G.P. remarque à cet égard que l'areligiosité est aux nouveaux Länder, ce que l'appartenance confessionnelle est aux Länder de l'Ouest : la norme est en somme inversée selon que l'on provient de R.F.A. ou de R.D.A. À cet égard, la très intéressante contribution de Albrecht Döhnert à propos de la perpétuation de la Jugendweihe permet de comprendre les raisons de la persistance de cette culture politique a-religieuse. Le succès que connait ce rituel encore aujourd'hui renvoie non seulement à la situation d'anomie dans laquelle l'effondrement du régime a plongé la population est-allemande mais aussi au besoin de transmettre une mémoire est-allemande dans l'Allemagne réunifiée. Döhnert montre ainsi comment la pratique de ce rituel constitue pour les Allemands de l'Est un vecteur de continuité symbolique avec le passé tout en leur permettant de se positionner sur le marché des normes et des valeurs religieuses ou humanistes de l'Allemagne réunifiée. Ce faisant, il met en relief les transformations d'un rituel qui devient une option personnelle et se réinscrit dans la tradition humaniste allemande. Ce n'est évidemment pas la seule explication de cette "stagnation religieuse » des Länder de l'Est qui intrigue tant les sociologues de la religion. D'autres facteurs sont invoqués, et parmi eux, le discrédit dont ont souffert les Eglises protestantes est-allemandes à la suite de l'ouverture des archives de la Stasi ainsi que l'incompréhension des chrétiens d'Allemagne de l'Est à l'égard du statut des Églises dans la société. Mais au regard des frustrations est-allemandes par rapport à une réunification, qui s'est traduite par une quasi absorption de l'Allemagne de l'Est par l'Allemagne fédérale, cette lecture identitaire a de quoi convaincre. 